\title{
Low-shrink airfield cement concrete with respect to thermal resistance
}

\author{
Małgorzata Linek $^{1, *}$ \\ ${ }^{1}$ Kielce University of Technology, al. Tysiąclecia Państwa Polskiego 7, 25-314 Kielce, Poland
}

\begin{abstract}
The paper presents theoretical background to the occurrence and propagation of imposed thermal load deep inside the structure of airfield pavement. The standard composition of low-shrink cement concrete intended for airfield pavements was presented. The influence of recurring temperature changes on the extent of shrinkage deformations was assessed. The obtained lab test results, combined with observations and analysis of changes of the hardened concrete microstructure, allowed the authors to draw conclusions. It was proven that the suggested concrete mix composition makes it possible to obtain the concrete type of better developed internal microstructure. More micro air voids and reduced distance between the voids were proven, which provides increased frost resistance of concrete. The change of size, structure and quantity of the hydration products in the cement matrix and better developed contact sections resulted in the improvement of the mechanical parameters of hardened concrete. Low-shrink concrete in all analysed cases proved to have increased resistance to the variable environmental conditions. Increased concrete resistance is identified through reduced registered shrinkage deformations and growth of mechanical parameters of concrete. Low-shrink concrete used for airfield structure guarantees extended time of reliable pavement operation.
\end{abstract}

\section{Introduction}

Thermal resistance of the airfield structure is defined as the ability to transfer diversified types of thermal load by pavement layers (especially pavement surfacing). Thermal loads of three types are generated onto airfield pavements. The first type includes loads generated as a result of the thermal processes occurring in the hardening concrete mix. The second type includes natural thermal loads occurring in concrete as a result of ambient temperature variations. The third type of thermal loads is the imposed loads. The factor which causes the occurrence of the imposed thermal loads on the airfield pavements are aircrafts in operation. Jet engines [1] suck the air, which combusts rapidly after being compressed and mixed with the fuel, thus producing a gas with high temperature and pressure. The gas gets out of the engine. Placing the engines under the aircraft wings contributes to directing the exhaust gas stream straight onto the pavements. The diameters of exhaust nozzles range between $0,45 \mathrm{~m}$ and $1,58 \mathrm{~m}$ [2]. The velocity of the gas stream emitted from aircraft engines is irregular, turbulent and it depends mainly on engine performance $[3,4]$. The width of stream of one engine is from $12 \mathrm{~m}$ to $20 \mathrm{~m}$. Parameters of exhaust gas stream at nozzle outlet reach the streamflow velocity of $500-600 \mathrm{~m} / \mathrm{s}$ and gas temperature of $530-900{ }^{\circ} \mathrm{C}$. In the case of turbine jet engines without afterburner, in external channel, the velocity of air stream is $300-400$ $\mathrm{m} / \mathrm{s}$ and its temperature is $30-230{ }^{\circ} \mathrm{C}[3]$.
Hot exhaust gas stream, after leaving the engine nozzle on contact with airfield pavement, spreads in ellipsoidal shape forming the so called "stream core". Core characteristics depend on the individual structure solutions of the aircraft power unit and geometry thereof. The core width usually ranges from 5 to $10 \mathrm{~m}$ and it spreads from 70 to $90 \mathrm{~m}$ behind the nozzle edge [3]. The local heating of airfield exceeds $200{ }^{\circ} \mathrm{C}$ [4] within this area. The highest temperatures of hot gas stream occur along the extension of the engine axis. The intensity of the impact of such temperatures increases, together with the increase of inclination angle of the longitudinal axis of the aircraft, with respect to the pavement vertical alignment. It ranges between approx. $140{ }^{\circ} \mathrm{C}$ at $0^{\circ}$ and over $520^{\circ} \mathrm{C}$ at $16^{\circ}[3]$.

Imposed thermal loads are multiple repeated gas stream impact of high kinetic energy and high temperature onto the pavement [3]. The turbine slope of the common aircraft structures is at a maximum of 2 to $3^{\circ}$ and the minimum nozzle height from the airfield surface $-1,3 \mathrm{~m}$. Taking into consideration such an assumption, the stream temperature at slab surface can reach even $250{ }^{\circ} \mathrm{C}$. Concrete pavement can be resistant to such temperature for a short period of time of 5-10 s, however, multiple repeated deformations cause structural concrete changes. Stream dynamics can cause pavement defects and its intensity lowers with the distance from the nozzle and within immediate vicinity thereof. During wintertime, at low ambient temperatures, the degree of gas stream impact on the surface changes. Repeated

\footnotetext{
Corresponding author: linekm@tu.kielce.pl
} 
influence of high temperatures in alternating freezing and defrosting of the surface pavement layer increases the temperature difference and the extent of deformations reduces pavement resistance and durability [2].

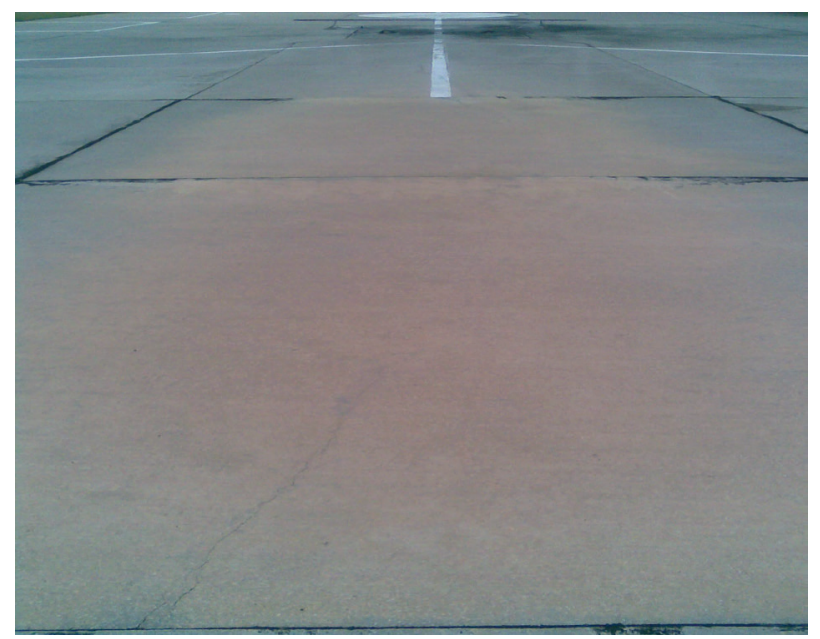

Fig. 1. Change of concrete colour within the area of the so called stream core on the airfield pavement.

Within the area of the pavement under operation, within the location where the exhaust gas meets the pavement, there are areas of changed colour [5]. Visually analysing the colour of concrete exposed to the influence of high temperatures, subject to the indirect method, the temperatures to which concrete was heated, were estimated. The colour of the analysed concrete within such areas changed from natural to dark grey, dark yellow and even yellow (Fig. 1).

Such colour proves the influence of temperatures ranging from $600{ }^{\circ} \mathrm{C}$ to $900{ }^{\circ} \mathrm{C}$ on the pavement. Independent of the process length, heating usually affects $0,003-0,005 \mathrm{~m}$ of the concrete slab external layer. Surface layer with a thickness of approximately 0,0010$0,0015 \mathrm{~m}$ (Fig. 2) is particularly exposed to the intensive influence of temperature. Even under short stream impact, the dynamics of the heat flow can cause pavement vibrations. Vibrations of undefined characteristics can be the reason for the intensity of the damages.

Due to the fact that the degree of exposure of the airfield pavement to the impact of hot exhaust gas depends, among other things, on the properties of the component materials of the concrete mix, it is advisable to modify the mix composition intended for airfield pavements. During the varying heating and cooling, the range of concrete stress changes. As a result of the immediate temperature and humidity changes, shrink deformations can occur, contributing to the occurrence of micro cracks of concrete. Heat inside the concrete will move from the surface layer - with a higher temperature, towards cooler areas - located lower. Water contained in concrete evaporation during heating and its volume increase can form additional stress areas in concrete structure. Interruption of concrete structure continuity during heating and cooling causes additional hydration, dehydration and reactions in solid reaction in concrete components. Insufficient consideration of temperature changes, caused by recurrent heating can result in concrete damage. Such damage, including the loss of concrete continuity, will be represented by the occurrence of cracks.

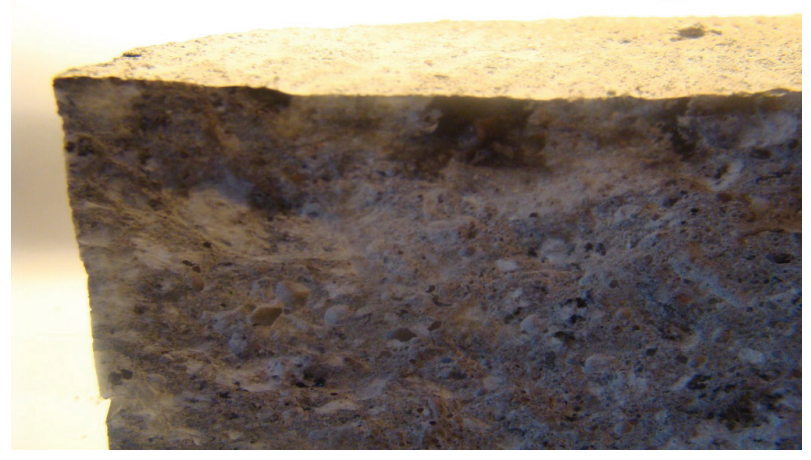

Fig. 2. Change of concrete colour.

\section{Purpose and scope of the research}

The purpose of this research is to define the influence of the applied modification of the concrete mix composition on the change of the parameters of hardened concrete exposed to the influence of imposed thermal loads. The analysis included determination of changes of basic mechanical parameters of concrete and determination of the extent of rheological deformations.

The research included two series of paving-grade concrete. Types of concrete of C40/50 class intended for the airfield pavements, complying with the requirements of $[6,7]$, were analysed. The first research series included concrete whose composition contained the materials recommended by the requirements of [7]. This concrete was defined as $\mathrm{CC}-1$. The results obtained in the case of CC-1 concrete were taken as reference values. The second research series was low-shrinkage concrete of modified composition (determination: CC-2). In CC-2 concrete composition, apart from materials consistent with the requirements [8-11], an optimum quantity (determined on the basis of pilot studies) of ceramic modifier in the form of dust was included. The following preliminary tests for both concrete types were conducted: compressive strength $f_{c m}$, tensile strength in bending $f_{c f}$ and flexural strength $f$ were determined. The tests were conducted, in accordance with the guidelines of the applicable standards [12-14] after the assumed curing period (28 days). The influence of the applied ceramic dust on the changes in compressive strength of concretes exposed to the influence of regular heating and cooling was determined $\left(\Delta f_{c m}\right)$. Prepared samples intended for laboratory tests were cured in water of temperature $20^{\circ} \mathrm{C} \pm 2{ }^{\circ} \mathrm{C}$ for the first 28 days $[15,16]$. Subsequent laboratory tests assumed the diversified number of test cycles. A single test cycle included the process of alternating heating and cooling - Table 1 . Recurrent influence of temperature stimulated the impact of aircraft on airfield pavement. The assumed heating and cooling time corresponded to the time during which the aircraft affected the most frequently used airfield 
pavement within the area of Poland. The velocity of gas stream emitted during the test was $30 \mathrm{~m} / \mathrm{s}$.

Table 1. Conditions assumed during the research.

\begin{tabular}{|c|c|c|}
\hline Concrete & Number of cycles & Curing conditions \\
\hline $\mathrm{CC}_{50}$ & 50 & $\begin{array}{c}\text { Heating: time: } 60 \mathrm{~s}, \\
\text { temperature: } 250{ }^{\circ} \mathrm{C} \pm 2{ }^{\circ} \mathrm{C} \\
\text { Cooling: time: } 900 \mathrm{~s}, \\
\text { temperature: } 20^{\circ} \mathrm{C} \pm 2{ }^{\circ} \mathrm{C}\end{array}$ \\
\hline
\end{tabular}

In order to assess the impact of the used ceramic dust on the changes of their internal structure, concretes were subject to observations in scanning electron microscope (SEM). Preparation of samples and interpretation of the obtained results were in compliance with those described in literature $[17,18]$. Fresh fractures were prepared using concrete CC-1 and CC-2. The preparation surface was observed by means of scanning electron microscope SEM and each time it was more than $1 \mathrm{~cm}^{2}$. The magnification ranged from 200x to $100000 x$.

During the basic tests, the values of shrinkage of concrete cured for the first 28 days and concrete exposed to the influence of variable thermal loads were defined.

\section{Research materials}

The assumed characteristics of aggregate composition (Table 2) determine the physical and mechanical parameters of hardened concrete and its resistance to the occurrence of shrinkage deformations. Granite grit was used in the total quantity of $1400 \mathrm{~kg} / \mathrm{m}^{3}$, out of which $37 \%$ was $2 / 8 \mathrm{~mm}$ fraction, $9 \%$ was $8 / 16 \mathrm{~mm}$ fraction and $32 \%$ was $16 / 32 \mathrm{~mm}$ fraction. In CC-1 mix, fine aggregate in the quantity of $415 \mathrm{~kg} / \mathrm{m}^{3}$ was included, while in the CC-2 mix it was included in the quantity of $370 \mathrm{~kg} / \mathrm{m}^{3}$. The change of aggregate quantity applied to the mixes resulted from the modifier contents. Aggregate compositions of the designed mixes (Table 2) were considered as good grain size distribution of airfield pavements. Mixes CC-I and CC-II included cement CEM I $42,5 \mathrm{~N}$ to the amount of $377 \mathrm{~kg} / \mathrm{m}^{3}$. Admixtures in the form of air entrainment agent $\left(1,7 \mathrm{~kg} / \mathrm{m}^{3}\right)$ and plasticizing admixture $\left(0,7 \mathrm{~kg} / \mathrm{m}^{3}\right)$ were used in these mixes.

Table 2. Aggregate compositions of the mixes.

\begin{tabular}{|c|c|c|c|c|}
\hline \multirow{2}{*}{$\begin{array}{c}\text { Size of the } \\
\text { reference sieve } \\
\text { mesh [mm] }\end{array}$} & \multicolumn{2}{|c|}{$\begin{array}{c}\text { Passes through the } \\
\text { sieve [\%] }\end{array}$} & \multicolumn{2}{c|}{ Mixtures curve [\%] } \\
\cline { 2 - 5 } & CC-1 & CC-2 & lower & upper \\
\hline 16,00 & 100,0 & 100,0 & 100 & 100 \\
\hline 11,20 & 83,6 & 80,4 & 79 & 85 \\
\hline 8,00 & 69,9 & 67,8 & 65 & 75 \\
\hline 5,60 & 58,3 & 60,9 & 49 & 61 \\
\hline 4,00 & 47,1 & 41,2 & 39 & 52 \\
\hline 2,00 & 33,6 & 27,5 & 25 & 40 \\
\hline 1,00 & 20,6 & 23,9 & 16 & 28 \\
\hline 0,50 & 11,6 & 13,4 & 9 & 18 \\
\hline 0,25 & 3,0 & 2,7 & 2 & 2 \\
\hline
\end{tabular}

\section{Testing methods}

For research purposes, shrinkage was defined as the difference in sample length. A basic measurement was the sample dimension measured directly after unforming thereof. This length referred to sample length in the course of its drying.

The extent of the observed shrinkage deformations is variable and depends closely on climatic conditions. It was assumed that defining the influence of the applied dust on the change in shrinkage deformations will take place in the case of five series. Each time, 6 samples of concrete CC-1 and CC-2 stored in the same environmental conditions were subject to the analysis. The first (A) series, reference series, included CC-1 and CC-2 concrete curing for the period of 28 days completely immersed in water with a temperature of $20{ }^{\circ} \mathrm{C}$. Series B and D included CC- 1 and CC- 2 concrete stored from the 28th day of curing in air-dry conditions. Series C and E included CC-1 and CC-2 concrete exposed to the influence of thermal cycles. The comparison of conditions during the test has been presented in Table 3.

Table 3. Test conditions for the research series (A-E).

\begin{tabular}{|c|c|c|c|c|c|}
\hline \multirow{2}{*}{ series } & Time & \multicolumn{2}{|c|}{ Temperature } & \multicolumn{2}{|c|}{ Humidity } \\
\hline & {$[\mathrm{s}]$} & \multicolumn{2}{|c|}{$\left[{ }^{\circ} \mathrm{C}\right]$} & \multicolumn{2}{|c|}{$[\%]$} \\
\hline A & 2419200 & \multicolumn{2}{|c|}{$20 \pm 2$} & \multicolumn{2}{|c|}{100} \\
\hline B & 48000 & \multicolumn{2}{|c|}{$20 \pm 2$} & \multicolumn{2}{|c|}{$46-64$} \\
\hline $\mathrm{C}$ & 48000 & $25 \pm 3$ & $20 \pm 2$ & $42-50$ & $56-65$ \\
\hline $\mathrm{D}$ & 96000 & \multicolumn{2}{|c|}{$20 \pm 2$} & \multicolumn{2}{|c|}{$46-64$} \\
\hline $\mathrm{E}$ & 96000 & $28 \pm 2$ & $20 \pm 2$ & $40-47$ & $56-65$ \\
\hline
\end{tabular}

In order to determine single shrinkage of $\mathrm{CC}-1$ and CC-2 concrete lots A, B, C, D and E 6 samples were used, in accordance with the guidelines [18], in the form of beams with a cross section of $150 \times 150 \times 600 \mathrm{~mm}$. Changes in sample length in the course of their drying were measured by means of a measuring instrument of reading capacity of more than $0,005 \mathrm{~mm}$. Directly after removing each sample from a mould, the locating distance lo was determined. Socket extensometer and benchmarks stuck with a quick-drying glue to the sample surface were used.

The assumed frequency of measurement series A performance was determined every 2 days in the period between the $1^{\text {st }}$ and the $10^{\text {th }}$ day, every 4 days for the period between the $7^{\text {th }}$ and $28^{\text {th }}$ day. The assumed frequency of measurement series B, C, D and E performance was determined every 2 days for the entire period.

The adopted research procedure complies with the instructions [18]. In the case of each analysed sample, after specified time, shrinkage deformation was determined $\varepsilon_{s}$, according to formula (1), in which $d_{0}$ is initial-basic distance (directly after unforming) between measurement points and $d_{t}$ is the distance determined after the expected drying time:

$$
\varepsilon_{s}=\left(d_{0}-d_{t}\right) / d_{0} .
$$


Selected samples of CC-1 and CC-2 concrete subject to 50 and 100 thermal cycles were observed in a scanning electron microscope. During observation, special attention was paid to the structure of the contact areas between aggregate grains and cement matrix, porosity characteristics and changes of cement matrix crystallization.

\section{Results and discussions}

On the basis of the analysis of the obtained destructive test results, it was proven that $\mathrm{CC}-2$ series concrete, regardless of the analysed feature, is distinguished by more favourable mechanical parameters (Table 4). In the case of compressive strength, after 28 days of curing in standard conditions, CC-2 concrete reached slightly higher compressive strength values. In the case of tensile strength, there is a significant growth in the tested feature of $18 \%$. With reference to the airfield pavements, the flexural strength is identified with operational durability of pavement. And its higher value refers to higher fatigue limit of concrete. Also, in the case of flexural strength, higher parameters of CC-2 concrete were observed.

Table 4. Mechanical parameters ( $\bar{X}$ - average value [MPa], $\sigma$ - standard deviation).

\begin{tabular}{|c|c|c|c|c|c|c|}
\hline \multirow{2}{*}{ Concrete } & \multicolumn{2}{|c|}{$f_{c m}$} & \multicolumn{2}{c|}{$f$} & \multicolumn{2}{c|}{$f_{\text {cf }}$} \\
\cline { 2 - 7 } & $\bar{X}$ & $\sigma$ & $\bar{X}$ & $\sigma$ & $\bar{X}$ & $\sigma$ \\
\hline CC-1 & 57,0 & 0,04 & 6,1 & 0,05 & 4,76 & 0,05 \\
\hline CC-2 & 59,4 & 0,03 & 7,3 & 0,03 & 5,59 & 0,04 \\
\hline
\end{tabular}

According to the obtained results from the shrinkage deformation analysis it was proven that dust additive used in the composition of CC-2 concrete has significant impact on the extent of reduced shrinkage (Table 5). Regardless of environmental conditions and the time of thermal cycles influence, $\mathrm{CC}-2$ concrete is distinguished by reduced deformations. It was proven that $\mathrm{CC}-\mathrm{1}^{\mathrm{A}}$ concrete cured for 28 days in water with a temperature of $20^{\circ} \mathrm{C}$ is distinguished by a deformation of $0,0417 \%$, while in the case of $\mathrm{CC}-2^{\mathrm{A}}$ concrete this value does not exceed $0,0150 \%$ (Table $5-\mathrm{A}$ series). It was proven that change in the curing conditions (series $\mathrm{B}$ and $\mathrm{C}$ and series $\mathrm{D}$ and $\mathrm{E}$ ) also influences the phenomenon of increased shrinkage deformations. Samples of CC-1 and CC-2 concrete stored for 50 and 100 cycles in air-dry conditions (average temperature of $20^{\circ} \mathrm{C}$ and humidity range of 46-64\%) are distinguished by average deformation lower than in case of thermal cycles. In each of these cases, deformations of CC-2 concrete are significantly lower than in CC-1 concrete. Deformations of $\mathrm{CC}-1^{\mathrm{B}}$ concrete amount to $0,000128 \%$ and they are greater by order of magnitude than deformation of CC$2^{\mathrm{B}}$ concrete. Similar tendency is also observed after extending the period with subsequent 50 thermal cycles. The average deformation in $\mathrm{CC}-1^{\mathrm{D}}$ concrete is $0,000135 \%$, while in $\mathrm{CC}-2^{\mathrm{D}}$ concrete it is only $0,000071 \%$. A favourable phenomenon is also the fact that with $\mathrm{CC}-2$ concrete, the growth of deformations after 100 cycles is lower than after 50 cycles. It is evidenced by the fact of the favourable influence of the applied dust on the reduction of deformations within a longer period of time. This phenomenon was also proven by the conducted compressive strength tests. The tested feature of CC-2 concrete after 56 days of curing was $63,7 \mathrm{MPa}$ and it was higher by 4,5 $\mathrm{MPa}$ than the resistance of CC-1 concrete. It was proven that $\mathrm{CC}-2$ concrete exposed to alternating thermal cycles is distinguished by significantly less shrinkage deformation. It should be emphasized that deformations observed in CC-2 concrete, in each of the discussed cases, reached significantly lower values than those of CC-1 concrete (Fig. 3).

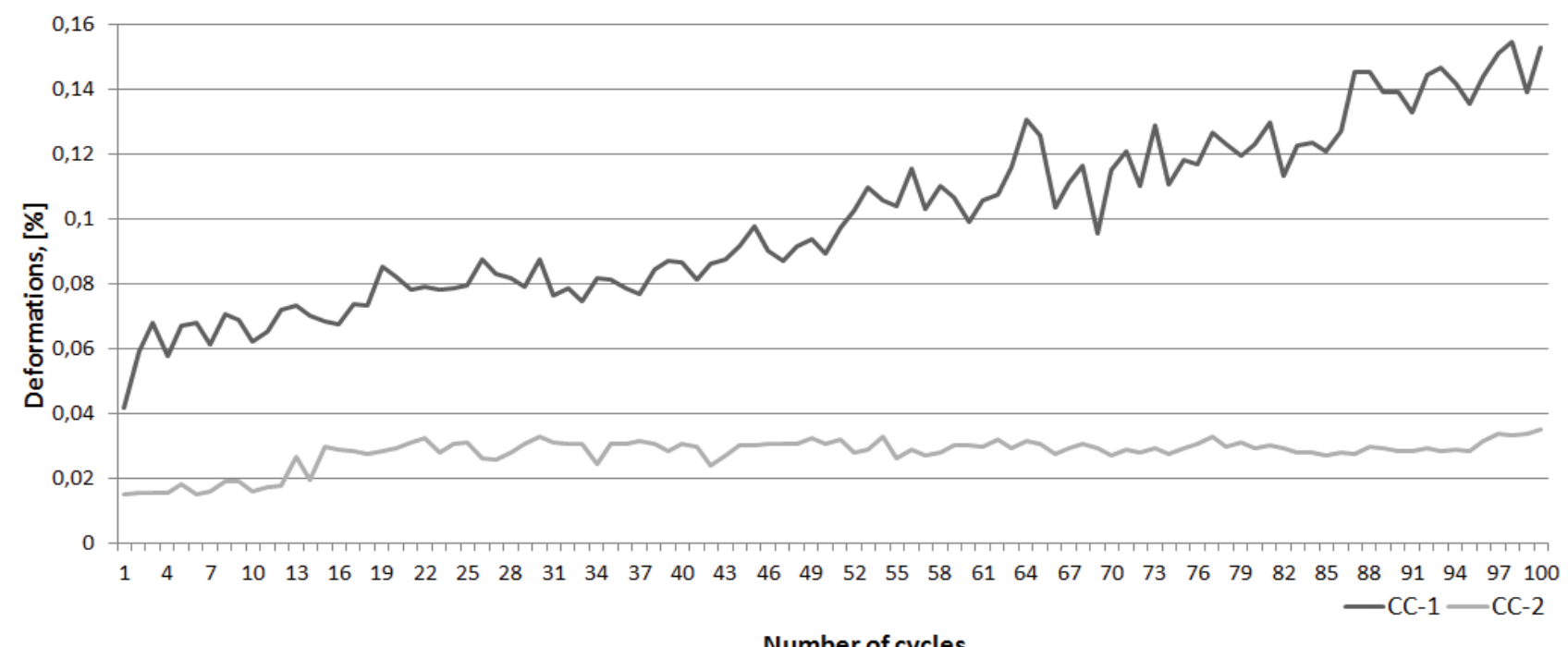

Fig. 3. Deformation of concrete CC-1 and CC-2. 
Table 5. Increasing shrinkage deformations of CC-1 and CC-2 concrete in various conditions (where: T indicates days, $\varepsilon_{\mathrm{p}}$ indicates initial deformation [\%], and $\varepsilon_{\mathrm{k}}$ indicates final deformation [\%]]).

\begin{tabular}{|c|c|c|c|c|c|c|c|}
\hline \multirow{2}{*}{ series } & $\mathrm{T}$ & \multicolumn{3}{|c|}{ Concrete CC-1 } & \multicolumn{3}{c|}{ Concrete CC-2 } \\
\cline { 2 - 8 } & {$[$ days $]$} & $\varepsilon_{p} \div \varepsilon_{k}$ & $\varepsilon_{k}-\varepsilon_{p}$ & $\frac{\varepsilon_{k}-\varepsilon_{p}}{t}$ & $\varepsilon_{p} \div \varepsilon_{k}$ & $\varepsilon_{k}-\varepsilon_{p}$ & $\frac{\varepsilon_{k}-\varepsilon_{p}}{t}$ \\
\hline $\mathrm{A}$ & 28 & $0,0012 \div 0,0417$ & 0,0405 & $1,45 \times 10^{-3}$ & $0,0004 \div 0,0150$ & 0,0146 & $5,21 \times 10^{-4}$ \\
\hline $\mathrm{B}$ & 13,3 & $0,0417 \div 0,0434$ & 0,0017 & $1,28 \times 10^{-4}$ & $0,0150 \div 0,0161$ & 0,0011 & $8,27 \times 10^{-5}$ \\
\hline $\mathrm{C}$ & 13,3 & $0,0417 \div 0,0977$ & 0,0056 & $4,21 \times 10^{-4}$ & $0,0150 \div 0,0327$ & 0,0018 & $1,35 \times 10^{-4}$ \\
\hline $\mathrm{D}$ & 26,6 & $0,0417 \div 0,0453$ & 0,0036 & $1,35 \times 10^{-4}$ & $0,0150 \div 0,0169$ & 0,0019 & $7,14 \times 10^{-5}$ \\
\hline $\mathrm{E}$ & 26,6 & $0,0417 \div 0,1547$ & 0,1094 & $4,11 \times 10^{-3}$ & $0,0150 \div 0,0352$ & 0,0202 & $7,59 \times 10^{-4}$ \\
\hline
\end{tabular}

Physical and mechanical parameters (among others, average compressive strength and flexural strength) are internal concrete structure derivatives. The following factors influenced, among others, the concrete structure of series I and II: air voids characteristics, occurrence of aggregate grains (fine, coarse and ceramic dust) of various mineral composition and diversified shapes and dimensions, structure of cement matrix and contact area between matrix and grains. Modification of concrete mix composition of series II with ceramic dust, contributed to the provision of concrete of better developed internal structure. According to the observation made of CC-1 and CC-2 series concrete by means of SEM, after 28 days of curing and exposure to thermal cycles it was proven that the influence of the alternating heating and cooling cycles contributes to significantly unfavourable changes in the microstructure of the hardened concrete.

The microstructure of CC- $1^{50}$ and CC- $1^{100}$ concrete, in comparison to CC-1 concrete, showed a change in the upper, surface layer of a sample exposed to the influence of exhaust gas. This layer is distinguished by the increased concentration of carbonates and increased porosity and width of micro scratches. In matrix, crystallization of fine-grained hydrated calcium silicates of type C-S-H prevails. There are also cracked aggregate grains (Fig.4).
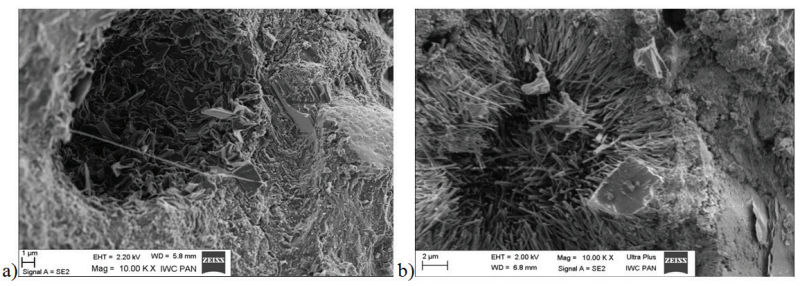

Fig. 4. Microstructure diversification: a) concrete CC-1 and b) concrete $\mathrm{CC}-1^{50}$.

The microstructure of $\mathrm{CC}-2^{50}$ and $\mathrm{CC}-2^{100}$ concrete as compared to $\mathrm{CC}-2$ is distinguished by a change within the surface area, accumulation of carbonates, increased porosity and a few scratches. Ettringite crystals occur inside air voids. Contact areas of cement matrix with aggregate grains remain uninterrupted (Fig. 5).

The microstructure of $\mathrm{CC}-2^{50}$ and $\mathrm{CC}-2^{100}$ concrete when compared with $\mathrm{CC}-1^{50}$ and $\mathrm{CC}-1^{100}$ concrete demonstrated a lower influence of temperature within the surface layer. Scratches in the modified concrete occur less often than in the reference concrete, at the same time they are distinguished by a smaller width. In the case of voids in both types of concrete, crystallization of ettringites prevails, however crystals in CC- 1 concrete are predominantly bigger than in $\mathrm{CC}-2$ concrete. In the matrix of $\mathrm{CC}-2$ concrete prevail finegrained hydrated calcium silicates of type C-S-H, whereas contact areas with aggregate grains remain uninterrupted (Fig. 6).

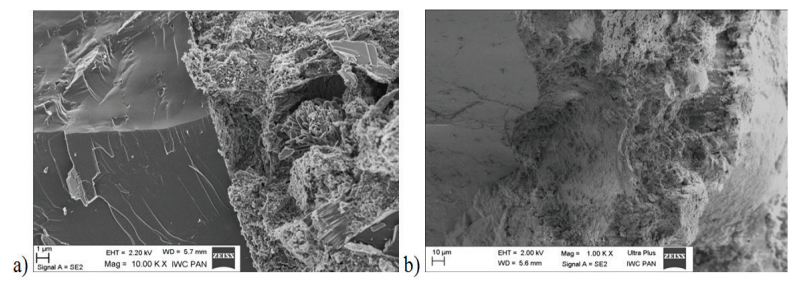

Fig. 5. Microstructure diversification: a) concrete $\mathrm{CC}-2$ and b) concrete $\mathrm{CC}-2^{50}$.

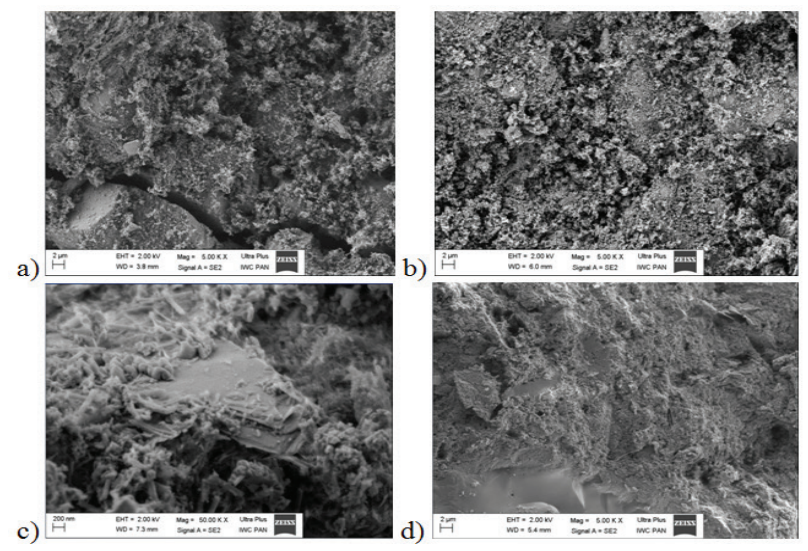

Fig. 6. Microstructure diversification of cement matrix: a) and c) concrete $\mathrm{CC}-1^{50}, \mathrm{~b}$ ) and d) concrete $\mathrm{CC}-2^{50}$.

\section{Conclusions}

On the basis of the tests, which have been conducted, the following conclusions were drawn:

a) Application of dust in the mix favourably influences the changes in concrete micro structure. In the case of CC-2 concrete, the content of distinguished components and their mutual ratios changes with respect to CC-1 concrete. In CC-2 concrete, stored in standard conditions and subjected to heating cycles, there were uninterrupted contact areas between aggregate grains and cement matrix. Discontinuities in the cement matrix 
occurred rarely and their width did not exceed $6 \mu \mathrm{m}$. The microstructure of CC-1 concrete was distinguished by significant number of micro cracks occurring both in cement matrix and contact areas with aggregate grains. Micro cracks width was varied and strictly dependant on curing conditions and areas of occurrence. The process of micro cracks formation in the case of CC-1 concrete clearly increased heating cycles. In the case of $\mathrm{CC}-2$ concrete, less developed ettringite crystallization occurred (the length of single crystals did not exceed $10 \mu \mathrm{m})$ and different, clearly fine-grained C-S-H phase than in CC-1 concrete.

b) Application of dust in the mix favourably influences the changes occurring in concrete porosity characteristics. In the case of CC-1 concrete, air voids were located within greater distances than in $\mathrm{CC}-2$ concrete. Moreover, the diameters of these voids were much bigger than in those in $\mathrm{CC}-2$ concrete. General air voids content in $\mathrm{CC}-1$ concrete was $2,2 \%$, and $3,7 \%$ in CC-2 concrete.

c) The application of dust in the mix significantly influences the reduction of observed rheorogical deformations of hardened concrete. With concrete cured at a temperature of $20{ }^{\circ} \mathrm{C}$, deformations in CC- 2 concrete are almost three times less than in $\mathrm{CC}-1$ concrete. When the curing period is extended, $\mathrm{CC}-2$ concrete provides higher resistance to the occurrence of shrinkage deformations. The observed average deformation for this type of concrete is $0,0000827 \%$ after 13,3 days and $0,0000714 \%$ after 26,6 days and they are lower in magnitude than in CC-1 concrete. The most significant influence of dust on the reduction of deformation was seen in concretes exposed to the influence of alternating heating and cooling cycles. Deformation in CC-1 concrete exposed to 50 thermal cycles is $0,000421 \%$, and in CC-2 concrete it is only 0,000135\%. A much more significant reduction in deformation was observed after 100 thermal cycles. In the case of CC-1 concrete, deformation amounted to $0,00411 \%$ and in the case of CC-2 concrete it was $0,000759 \%$.

d) The application of dust in the mix favourably influences the changes in porosity characteristics and internal structure of $\mathrm{CC}-2$ concrete, which results in obtaining low-shrinkage concrete.

\section{References}

1. A. Jankowski, Theses Air Force Institute of Technology, 28, (2010)

2. M. Linek, Surface concrete with improved parameters of physical and mechanical on the loads caused by forced temperature, $\mathrm{PhD}$ Thesis, Kielce, (2013)

3. P. Nita, Concrete surface airport. Theory and structural dimensioning, Publishing Air Force Institute of Technology, (2005)

4. B. Trigoni, Struinnaja erozja aerodromow, Transport, (1981)

5. M. Linek, P. Nita, Problems of research and operation of aviation technology, 9, 85-100, (2016)
6. PN-EN 206-1 Concrete-Part 1: Specification, performance, production and conformity

7. NO 17-A204:2015 Airfield concrete pavements Requirements and test methods for cement concrete pavements (2015)

8. M. Linek, P. Nita, The impact of the ceramic modifier on selected characteristics of the physical and mechanical properties of concrete pavement airport, VII Conference Dni Betonu, 83-92, (2012)

9. M. Linek, P. Nita, Influence of ceramic additive on the size of rheological deformations of airfield pavement concrete, IX Conference Dni Betonu, 131142, (2016)

10. M. Linek, P. Nita, Journal of KONES, 231 (2016)

11. M. Linek, Low Shrinkage Cement Concrete Intended For Airfield Pavements, in print, (2017)

12. PN-EN 12390-3:2011, Testing hardened concrete Part 3: Compressive strength of test specimens

13. PN-EN 12390-5:2011 Testing hardened concrete Part 5: Flexural strength of test specimens

14. PN-EN 12390-6:2011 Testing hardened concrete Part 6: Tensile splitting strength of test specimens

15. PN-EN 12390-1:2013 Testing hardened concrete Part 1: Shape, dimensions and other requirements for specimens and moulds

16. PN-EN 12390-2:2011 Testing hardened concrete Part 2: Making and curing specimens for strength tests

17. M. A. Glinicki, Durability of concrete in road surfaces. Effect of microstructure, materials design, diagnostics, Road and Bridge Research Institute, (2011)

18. ITB Instruction No 194/98, Study of mechanical properties of concrete on samples taken in the forms, Building Research Institute, (1998) 